\title{
NOTAS SOBRE A HISTÓRIA AMBIENTAL E SUA TRAJETÓRIA NA ITÁLIA
}

\author{
REMARKS ON ENVIRONMENTAL HISTORY AND ITS TRAJECTORY IN ITALY
}

\author{
Gil Karlos Ferri ${ }^{1}$ \\ José Carlos Radin ${ }^{2}$
}

Resumo: Este artigo apresenta um breve balanço sobre o aparecimento da História Ambiental e a sua trajetória na Itália, destacando alguns dos principais pesquisadores e suas obras. $\mathrm{O}$ viés histórico-ambiental desenvolveu-se na península por meio de um peculiar diálogo entre a geografia das paisagens, a História Agrícola e a História Econômica - campos de proeminência italiana. A relevância da crítica socioambiental se justifica, pois a História aponta para a possibilidade de que as experiências passadas possam ajudar na elaboração de soluções contemporâneas.

\section{Palavras-chave: Historiografia;} História Ambiental; Itália.

\begin{abstract}
This article seeks to present a brief balance on the appearance of Environmental History and its trajectory in Italy, evidencing the main researchers and their works. Although incipient, the historical environmental bias developed in the peninsula through a peculiar dialogue between the geography of the landscapes, the Agricultural History and the Economic History - fields of Italian prominence. The relevance of socio-environmental criticism through history is justified, because the future is, in parts, dramatically in our hands, and the History points to the possibility that past experiences may help in the elaboration of future solutions.
\end{abstract}

Keywords: Historiography; Environmental History; Italy.

\section{Contextualizando a História Ambiental}

Durante o século XX, a História ampliou e aprofundou seus temas de pesquisa, incorporando fontes e métodos de diversas ciências. Neste contexto surgiu a História Ambiental, como uma dilatação e hibridização do fazer historiográfico com diversas ciências naturais e sociais, visando o entendimento das interações humanas com o meio ambiente. Algumas de suas raízes podem ser encontradas em trabalhos geridos ou influenciados por Frederick Turner e pelos Annales, com Fernand Braudel, Lucien Febvre e Emmanuel Le Roy Ladurie. Porém, a sistematização da análise socioambiental é fruto

\footnotetext{
${ }^{1}$ Mestrando no Programa de Pós-Graduação em História da Universidade Federal da Fronteira Sul UFFS, Campus Chapecó - SC. E-mail: gilferri@ hotmail.com

${ }^{2}$ Professor Doutor do Programa de Pós-Graduação em História da Universidade Federal da Fronteira Sul

- UFFS, Campus Chapecó - SC. E-mail: radin@uffs.edu.br
} 
de uma sensibilidade ecológica desenvolvida a partir dos anos 1960 e 1970, sobretudo nos Estado Unidos e na Europa. Foi a partir da percepção da crise ambiental e da ação destrutiva da espécie humana que o meio ambiente despontou como temática amplamente dispersa nas sociedades mundiais, demandando à História uma revisão do passado que considerasse a natureza em sua vital importância para a trajetória humana sobre o planeta.

O tema do meio ambiente situa-se num contexto histórico em que as mais diversas questões ambientais passaram a fazer parte das preocupações cotidianas das sociedades em geral, também provocadas pela ideia da possibilidade de um colapso ambiental. Tais questões passaram gradativamente a ganhar importância não apenas nos espaços midiáticos, mas principalmente nos acadêmicos, provocando um conjunto cada vez mais significativo de pesquisas e debates. Nessa perspectiva, para melhor compreender tal fenômeno, faz-se necessário ter em mente a forma de como o sistema produtivo vem se apropriando dos recursos naturais, em particular a partir do avanço e consolidação da industrialização, processo do qual decorreu a produção cada vez mais acelerada de bens de consumo. Com isso, salienta-se que as preocupações com o meio ambiente também estão condicionadas pelos problemas do nosso tempo, em especial, ligados à forma de organização do sistema produtivo.

Os anos setenta representaram um importante período para o amadurecimento de uma consciência ecológica e, por conseguinte, para o aparecimento de uma história com viés ambiental. O ano de 1970 foi marcado por simbolismos ligados à comemoração do primeiro Dia Mundial da Terra (22 de abril) e a sua designação como Ano Europeu da Conservação da Natureza. Em 1972 foi realizada em Estocolmo, na Suécia, a Conferência das Nações Unidas sobre o Meio Ambiente Humano, considerada um marco para a valorização de uma agenda governamental voltada aos assuntos ambientais. A crise petrolífera de 1973 gerou impactos mundiais não apenas no aspecto econômico, mas também na percepção acerca da finitude dos recursos naturais, pois ficou evidente que o crescimento desencadeado pela Revolução Industrial possui limites físicos. Neste contexto, alguns expoentes das sociedades de países desenvolvidos, mais sensíveis ao incipiente ambientalismo, foram precursores em pesquisas para interpretar as interferências humanas na natureza. Para citar exemplos, merecem destaque as obras de dois biólogos estadunidenses: o livro Silent Spring (1962), de Rachel Carson, pioneiro ao alertar para os efeitos nocivos dos pesticidas sobre todas as formas de vida, especialmente a humana; e The Closing Circle (1971), de Barry Commoner, que apresenta a ecosfera como um ciclo dinâmico de fenômenos fisioquímicos e biológicos. Na análise de 
Commoner, o sistema econômico moderno rompeu a dinâmica cíclica da ecosfera, transformando os antigos ciclos autorregulados em eventos humanos de aspecto linear e desequilibrados, colocando em perigo a capacidade de regeneração dos recursos vitais do planeta. Num cenário de crises, essas e outras constatações científicas influenciaram o incipiente movimento ambientalista que, por sua vez, disseminou-se pelo mundo e despertou o interesse e a opinião pública - sobretudo da classe média de algumas nações desenvolvidas - para as mais variadas questões ecológicas (ARMIERO, 2004, p. 24).

No campo historiográfico, desde a antiguidade as questões ambientais estiveram presentes em diversos trabalhos, porém, raramente constituíram o foco da análise e/ou foram problematizadas de modo sistematizado. A partir de meados do século XX, a crítica histórico-ambiental amadureceu paralelamente aos debates ecológicos desenvolvidos em diversas ciências. Por um lado, a estruturação de uma história conectada ao meio ambiente foi uma resposta aos apelos de uma sociedade que procurava cada vez mais entender a relação homem $x$ natureza através dos tempos; por outro, foi o resultado de um processo de renovação epistemológica da própria ciência histórica, que buscou ampliar e aprofundar suas temáticas e metodologias para compreender o passado, instrumentalizar criticamente o presente e, quiçá, vislumbrar melhores práticas para o futuro.

Assim como toda prática humana, a escrita da história é permeada por escolhas, exclusões e omissões. Ao que tudo indica, os historiadores contemporâneos internalizaram a consciência sobre essas inevitáveis relações de poder, pois, superadas as interpretações estreitas da história, executam seus trabalhos conforme a luz de uma ciência dialética e sempre provisória. Nada é mais global do que a relação humana com a natureza, sendo um dos pressupostos da pesquisa histórico-ambiental a sua capacidade de extrapolar fronteiras. Dito isso, justifica-se a opção deste artigo em apresentar a História Ambiental por um viés italiano, com o propósito de estabelecer relação com algumas de suas preconizadas origens estadunidenses. O objetivo da narrativa consiste em apresentar um breve histórico dos estudos socioambientais, algumas obras relevantes e as notáveis contribuições deste campo de estudo na Itália.

\section{A História Ambiental na Itália}

De todos os continentes, possivelmente a Europa tenha sido o que mais estabeleceu contatos com outras áreas do globo terrestre. Não seria possível compreender a história e a identidade europeia sem considerar suas relações materiais, biológicas e 
culturais com o restante do mundo. De modo geral, podemos identificar nestas intensas trocas uma das raízes para o desenvolvimento de um ímpeto científico/pesquisador no Velho Mundo. Seguindo a vanguarda em diversos campos de pesquisa, atualmente a temática ambiental desponta com significativa relevância entre os pesquisadores europeus. Ao nível governamental, e a título de exemplo, podemos identificar o impacto positivo de uma política ambiental comunitária executada pela União Europeia. Apesar das dificuldades, tais políticas possuem a capacidade de afrontar problemas transfronteiriços e impelir diversos países a adotar uma política ambiental que responda a alguns requisitos mínimos estabelecidos a nível europeu SCICHILONE, 2008). E na Itália, quais foram as trajetórias, as principais obras e o atual estado da arte das pesquisas em História Ambiental?

Na Itália, em comparação aos países de língua inglesa, a História Ambiental foi absorvida com certo atraso. Até meados do século XX, a historiografia italiana foi marcada por duas principais heranças: o marxismo e o idealismo. Para os marxistas, grosso modo, a sociedade deveria ser entendida a partir do trabalho e do capital, sem cair em determinações naturais; enquanto que para os idealistas, a análise deveria concentrarse nas estruturas puramente sociais, pois os elementos naturais seriam alheios às expressões humanas. A resistência da historiografia italiana à análise histórico-ambiental também se deveu ao fato de que a consciência ecológica demorou a configurar-se num tema de forte relevância social e acadêmica em um país marcado pelo ideal progressista e com industrialização ainda em curso no final do século XX (ARMIERO, 2004, p. 49).

Podemos constatar que na península itálica os temas ambientais partiram de historiadores envolvidos com a agricultura e a economia. Aos poucos, a partir dos anos 1950 e 1960, as pesquisas em História Agrícola passaram a englobar questões de caráter ambiental. Porém, uma disciplina sistemática, aos moldes da Environmental History estadunidense, só teve algum reconhecimento entre os historiadores italianos no final da década de 1980, de modo extemporâneo e fragmentado (PICCIONI, 2014, p. 03).

Muitos intelectuais passaram a dispensar atenção para as questões ambientais por meio da ligação ou influência do Clube de Roma. O grupo, que reúne pessoas ilustres e cientistas de diversos países, foi fundado em 1966 pelo industrial italiano Aurelio Peccei e pelo cientista escocês Alexander King, e tem como objetivo o debate de diversos temas, sobretudo política, economia, meio ambiente e desenvolvimento sustentável. Sob encomenda do Clube, em 1972 foi publicado o relatório intitulado I Limiti dello Sviluppo, sob a organização da cientista ambiental Donalla ("Dana”) H. Meadows, apresentando ao 
mundo um impactante alerta sobre o esgotamento dos recursos naturais perante o aumento populacional. O relatório tornou-se um livro, traduzido em 28 idiomas e com mais de 30 milhões de cópias, tornando-se um dos livros sobre meio ambiente mais vendido até então (MEADOWS et. al., 1972).

Os exames de algumas produções no campo histórico-ambiental italiano acenam para uma espécie de história agrícola e geográfica. Tais estudos são referenciados por estudiosos como Emilio Sereni (1907 - 1997), Alberto Caracciolo (1926 - 2002) (CARACCIOLO, 1988 e 1990) e Lucio Gambi (1920 - 2006) (GAMBI, 1972 e 1973). Como exemplo, destaca-se a obra La storia del paesaggio agrario italiano, de Emilio Sereni, que colocou em evidência a agricultura e a paisagem sob uma análise ambiental (SERENI, 1961). Também merece destaque o movimento de conservação dos bens histórico-culturais e ambientais, que ganhou força com a fundação da associação Italia Nostra, em 1955, e possui no intelectual Antonio Cederna (1920 - 1996) um de seus proeminentes influenciadores (PICCIONI, 2014, p. 368-369). As pesquisas de Giorgio Nebbia legaram um importante componente para a constituição de uma História Ambiental italiana, bem como a revista Altronocento e as iniciativas da fundação Luigi Micheletti (PICCIONI, 2009). Ainda relevantes nesse contexto, são as imagens e documentos reunidos em L'ambiente nella storia d'Italia, pela Fundação Basso (FONDAZIONE BASSO, 1989). Entre os pesquisadores que se dedicaram a história do clima, podemos citar Roberto Finzi (FINZI, 1986; FINZI in PINTO et. Al., 2002. p. 555568) e Guido Alfani (ALFANI, 2010).

No campo da história econômica, desde o início do século XX historiadores italianos se interessaram por questões relacionadas aos recursos naturais. Entre os pioneiros, destaca-se Giuseppe Prato, com seu estudo de 1913 sobre os combustíveis e a industrialização. No tocante às fontes energéticas, tema de alta relevância na península, o historiador econômico de maior reconhecimento foi Carlo Maria Cipolla, que passou a unir em sua análise as questões econômicas e ecológicas (CIPOLLA, 1966). Também se destaca a obra Storia economica e ambiente italiano (ca.1400 - 1850), de Guido Alfani, Matteo Di Tullio e Luca Mocarelli. Nela, os autores apresentam o histórico acerca das instituições que objetivaram regulamentar as interações entre a sociedade e a natureza, e os impactos econômicos das condicionantes ambientais, como o uso da água e da lenha fundamental fonte de energia para a economia pré-industrial (ALFANI \& MOCARELLI, 2012, p. 16-17). 
A história do uso dos recursos naturais aparece na Itália com uma forte ligação com a história econômica e social, e suas análises se concentraram, sobretudo, nas temáticas sobre a água e as florestas. Nessa temática, o historiador Piero Bevilacqua refletiu sobre a relação da sociedade italiana com os rios, apontando suas atitudes perante a disponibilidade de água, e, em alguns casos, o comportamento cooperativo na busca de soluções hídricas (BEVILACQUA, 1992, p. 88-89). Em outro estudo, sobre o Vale de Diano, na província de Salerno, Bevilacqua colocou em evidência os conflitos socioambientais dos interesses governamentais e privados sobre os recursos florestais e hídricos, em uma área de alta relevância ecológica. Desde 1991, a área tornou-se o Parque Nacional de Cilento, Vale de Diano e Alburni, sendo considerada, em 1997, uma reserva da biosfera e, em 2010, foi instituído pela UNESCO como o primeiro Geoparque da Itália (BEVILACQUA, 1996, p. 113-160).

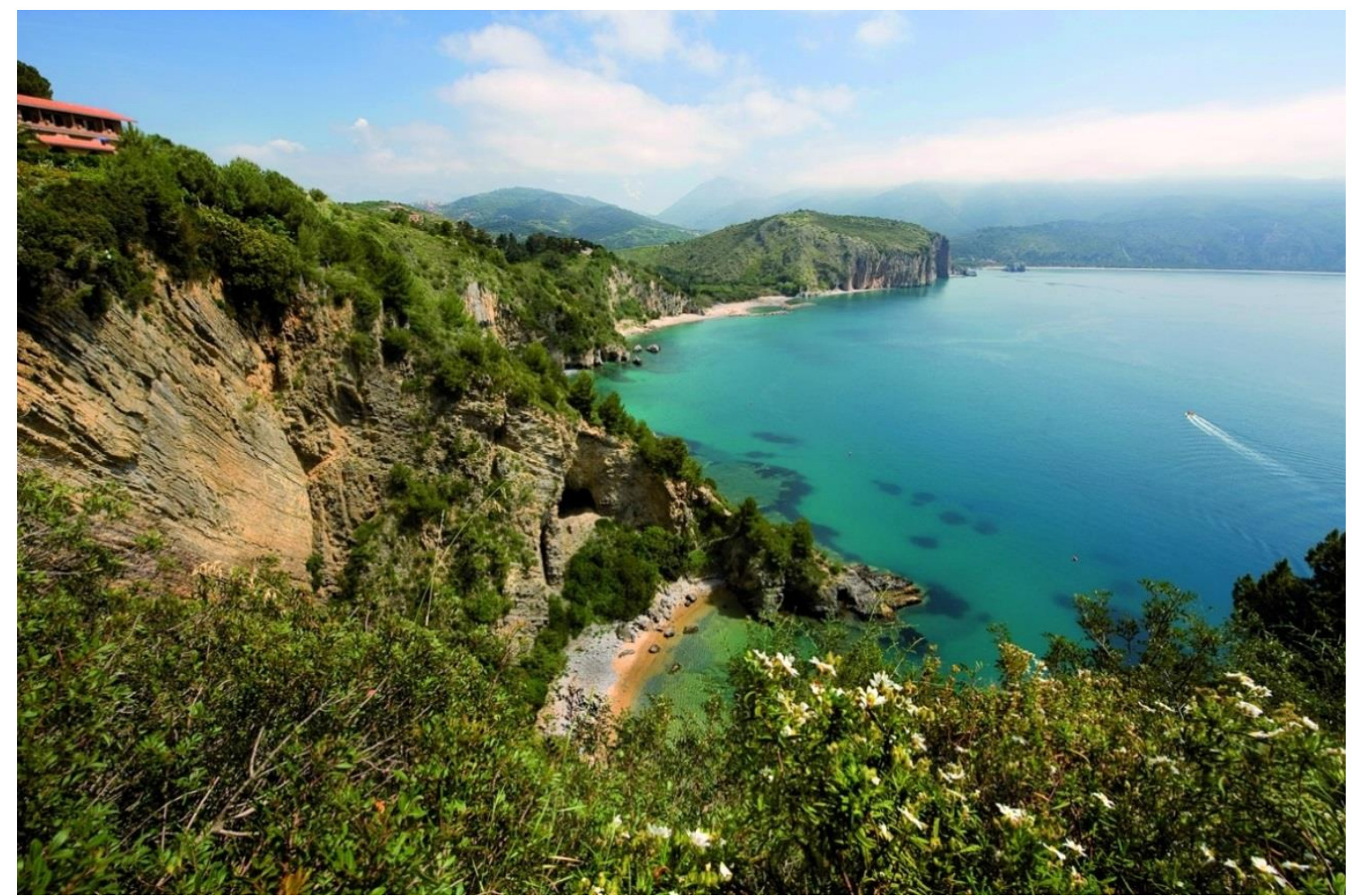

Vista parcial do Parque Nacional de Cilento, Vale de Diano e Alburni, província de Salerno, Sul da Itália. Foto: Panda B\&B Salerno, 2017.

De autoria de Giorgio Nebbia, La società dei rifiuti (1990) é um importante trabalho sobre produção, consumo e impactos ambientais. Na obra, o autor tece uma pertinente crítica histórica a crescente produção de lixo causada pelo consumismo, em uma sociedade marcada pela incapacidade de reutilizar matérias que poderiam ainda ser úteis (NEBBIA, 1990). 
Sobre a análise do meio ambiente e seus recursos energéticos, destacam-se as obras La cattura dell'energia, de Alberto Caracciolo e Roberta Morelli, e Energia e crescita nell'Europa preindustriale, de Paolo Malanima, ambas publicadas em 1996. Além do tema central, as fontes energéticas, os autores deram atenção a um longuíssimo período: desde a revolução neolítica até a Revolução Industrial. Na pertinente análise de Caracciolo e Morelli, não há história sem o uso dos recursos naturais, pois todos os seres vivos, sobretudo os seres humanos, demandam o uso de recursos energéticos no desenvolvimento de suas atividades (ALFANI \& MOCARELLI, 2012, p. 14).

Considerado um dos pioneiros da chamada ecologia histórica, Diego Moreno passou a observar a própria Terra como um documento carregado de história. A metodologia e as fontes adotadas por Moreno aproximaram a arqueologia florestal, a análise fóssil-polínica e a observação direta do sítio em estudo - os chamados studi sul campo, ou, em inglês, field study. Em suas pesquisas, Diego Moreno propõe uma visão que vai além das dicotomias como doméstico $x$ selvagem e culto $x$ inculto, demonstrando que, na realidade, tais concepções são confusas, sobrepostas e carregadas de subjetividade. Essa visão se constitui em importante crítica à historiografia italiana que, baseando-se em fontes normativas e prescritivas, como leis e tratados, acreditava que poderia descrever o ambiente; porém, na verdade, estava apenas narrando uma representação sua. Tal crítica trouxe, de fato, o ambiente para compor a história e compreender a interação entre a sociedade e a natureza. Obviamente as pesquisas desenvolvidas e propostas nessa área são complexas, e requerem do historiador um alto nível de entendimento das Ciências Naturais. Ou seja, aqui novamente o trabalho interdisciplinar aparece como requisito por excelência para os historiadores ambientais (MORENO, 1990).

Aspectos da relação entre a natureza e o catolicismo, tão caro aos italianos, aparecem nas observações do historiador estadunidense Lynn White (1907 - 1987). Para o historiador, o desprezo pela natureza e o ímpeto devastador da civilização ocidental possuem raízes na tradição judaico-cristã, que dessacralizou o meio ambiente e relegou ao ser humano a sua total utilização e dominação. White também chamou atenção para a figura histórica de São Francisco de Assis. Para além da hagiografia de seus milagres, o santo foi considerado o irmão dos elementos naturais e dos animais, e, na visão do historiador, um raro e radical antecipador da moderna relação harmoniosa entre o homem e o meio natural. Corroborando a sua observação, em 1979, o papa João Paulo II 
proclamou São Francisco o patrono da ecologia para a Igreja Católica (WHITE, 1973, p. 251-263).

Mais recentemente, novos trabalhos se dedicaram a compreender o uso dos recursos naturais sob o viés da História Ambiental. Publicado por Angelo Varni em 1999, Storia dell'ambiente in Italia tra Ottocento e Novecento apresentou questões de nível nacional, como a relação entre o desmatamento e o uso da água com a industrialização e a urbanização; mas também desenvolveu uma observação regional e micro, ao reconstituir a história da atividade mineradora e florestal na Sardenha (VARNI, 1999). No ano 2000, em um volume organizado por Piero Bevilacqua e Gabriella Corona, a observação recaiu sobre a inter-relação entre lugares físicos, como bosques, montanhas, e cidades, e o tratamento legislativo e burocrático dispensado pela elite política a estes lugares através dos tempos (BEVILACQUA \& CORONA, 2000). Sob a tutela de Andrea Filippo Saba e Edgar Meyer, com a introdução de Giorgio Nebbia, em 2001 foi apresentado o livro Storia ambientale: una nuova frontiera storiografica, no qual a narrativa concentra-se sobre a paisagem agrícola da planície lombarda e as implicações ambientais das políticas fascistas, e aponta o nascimento e a evolução do movimento ambientalista italiano (SABA \& MEYER, 2001). Fora da academia, merece citação a obra Storia della natura d'Italia, publicada por Fulco Pratesi, um dos fundadores e presidente do WWF (World Wide Fund for Nature) na Itália, na qual a narrativa histórica apresenta-se como um reprovável declínio que vai da exuberância da natureza à sua degradação por causas antrópicas (PRATESI, 2001). Em 2002, foi lançado o volume organizado por Simone Neri Serneri, sobre a paisagem da Toscana. Nesse livro, a historiografia é permeada por uma forte multidisciplinariedade, fazendo uma inteligente mistura entre geografia, sociologia, história agrícola, economia, estudos urbanísticos e direito. A obra expressa uma profícua continuidade com a tradição dos estudos sobre paisagem na Itália, e foi constituído através da hibridização de diversas áreas do conhecimento. Possivelmente, a mobilização de variados saberes representa um dos aspectos mais originais da historiografia ambiental italiana (SERNERI, 2002).

Por causa de suas origens agrárias, a História Ambiental italiana ainda não tratou com profundidade de temas recorrentes na análise histórico-ambiental americana, como a urbanização e a indústria. Avalia-se que a industrialização não foi muito estudada na Itália sob o viés socioambiental porque sua historiografia sempre foi motivada por uma visão progressista, que buscava no passado traços de sua modernização. Na realidade, durante a maior parte do século XX, a própria sociedade ainda não possuía em seu 
horizonte cultural os conceitos e instrumentos para avaliar tal experiência do ponto de vista ambiental, afinal, as contestações ecológicas estavam restritas a poucos indivíduos ligados ao nascente ambientalismo (MEYER, 1995, p. 09). De qualquer forma, trabalhos como Incorporare la natura: storie ambientali del Novecento, de Neri Serneri (2005), estão preenchendo essa lacuna, demonstrando as inter-relações socioambientais entre o campo e cidade no processo de urbanização e industrialização da Itália contemporânea (SERNERI, 2005, p. 37-38).

As lutas operárias de caráter ambientalista podem constituir uma temática privilegiada para a análise histórica. Neste sentido, a luta pela melhoria do meio ambiente e da qualidade de vida dos trabalhadores foi em parte descrita por Giulio Maccacaro (1924 - 1977), Raffaello Misiti (1925 - 1986), Giovanni Berlinguer (1924 - 2015) e outros estudiosos e ativistas envolvidos com o ambientalismo na Itália (NEBBIA, 1999).

Mesmo dentro da academia, a História Ambiental ainda é incipiente perante a totalidade das pesquisas realizadas. As principais estruturas científicas que promovem continuamente pesquisas histórico-ambientais são: o Istituto di Studi sulle Società del Mediterraneo, vinculado ao Consiglio Nazionale delle Ricerche (CNR) de Nápoles, que financia a revista I Frutti di Demetra: bolletino di storia e ambiente; e a Fondazione Luigi Micheletti, de Brescia, que, além de possuir um importante arquivo, publica a revista online Altronovecento: ambiente, tecnica e società (PAOLINI, 2011, p. 495). Porém, conforme a tradição diletante da Europa, há que se destacar que muitos autodidatas realizam pesquisas e publicam produções de caráter histórico, nas quais podemos encontrar, grosso modo, algum tipo do que hoje chamaríamos de análise socioambiental. Atualmente, podemos encontrar três campos de indagações na História Ambiental italiana: a história das crises, a história dos usos dos recursos naturais e a história da sensibilidade e da cultura ambiental. Porém, foi apenas nos últimos anos que a historiografia começou a confrontar-se com temas relativos a cultura e a sensibilidade ambiental. De acordo com Armiero e Barca, o relativo atraso na análise histórica acerca destes temas está associada, sem dúvidas, a escassa compreensão e adesão ao ambientalismo na sociedade italiana (ARMIERO \& BARCA, 2004, p. 52 e 55). Novos campos e indagações estão sendo explorados por historiadores ambientais. É o caso de Saverio Luzzi (LUZZI, 2009), que pesquisou a relação entre a poluição e a saúde pública, e Federico Paolini (PAOLINI, 2005, 2007 e 2009), autor de estudos sobre os meios de transporte e os impactos socioambientais. Para a Itália, Giorgio Nebbia aponta diversas 
temáticas para o desenvolvimento e aprofundamento de pesquisas em História Ambiental, sendo elas:

História da ecologia; história da conservação da natureza, história do ambiente; história da contestação ecológica; história das associações ambientalistas; histórias dos debates sobre "os limites da Terra". História das lutas operárias pela saúde e pelo ambiente de trabalho; história da economia ecológica e do direito ambiental; história das técnicas ecológicas; história da educação e das informações ambientais; história do caráter político dos movimentos de contestação; história da "ecologia dos patrões"; história da relação entre a Igreja e o ambiente; história das relações entre governos e ambiente; e a história das relações entre governo, poder e ambiente na Itália. ${ }^{3}$ Tradução livre.

Piero Bevilacqua, em sua obra Demetra e Clio: uomini e ambiente nella storia, apresenta uma sagaz síntese acerca dos enfrentamentos da História Ambiental. De acordo com Bevilacqua, a importância desse viés historiográfico consiste em analisar e unir Demetra, a deusa da Terra fértil, dotada de autonomia e força criativa, e Clio, a musa que representa a obra histórica das sociedades humanas. O livro é uma tentativa de olhar a história da relação homem-ambiente do ponto de vista de um "antropocentrismo sustentável": uma visão que não considera uma reconstrução meramente naturalística do passado, mas que saiba reconhecer a natureza nos processos econômicos e sociais, em sua presença autônoma e criativa na história (BEVILACQUA, 2001).

\section{Ecos do passado}

Apesar de relativamente recente na historiografia italiana, o viés ambiental apresenta relevantes contribuições. A partir dos primeiros insigths de historiadores envolvidos com a agricultura e a economia, a natureza foi ganhando espaço nas análises, sobretudo no tocante as paisagens e ao uso dos recursos naturais na península. Talvez a contribuição mais original da História Ambiental italiana encontre-se em sua peculiar hibridização entre a geografia das paisagens, a História Agrícola e a História Econômica.

Um dos slogans do ambientalismo é "pensar globalmente e agir localmente". Os historiadores ambientais parecem ter adotado esse ponto de vista convictos de que a partir

\footnotetext{
3 "Storia dell'ecologia; storia della conservazione della natura; storia dell'ambiente; storia della contestazione ecologica; storia delle associazioni ambientaliste; storia del dibattito sui "limiti della Terra"; storia delle lotte operaie per la salute e l'ambiente di lavoro; storia dell'economia ecologica e del diritto ambientale; storia delle tecniche ecologiche; storia dell'educazione e dell'informazione ambientale; storia del carattere politico dei movimenti di contestazione; storia dell'"ecologia dei padroni"; storia del rapporto tra le chiese e l'ambiente; storia dei rapporti frai governi e l'ambiente; e storia dei rapporti fra i governi, il potere e l'ambiente in Italia." Fonte: NEBBIA in SABA, \& MEYER, 2001, p. 11-35. Tradução livre.
} 
da observação do particular seja possível acessar e compreender o todo. A capacidade de dialogar com outros saberes e de dilatar o campo de observação proporcionou à História Ambiental uma visão que vai além das estruturas artificiais do mundo contemporâneo, demonstrando que a natureza nunca esteve ausente da história. Além do mais, esta historiografia aponta para a possibilidade de que experiências passadas possam ajudar na elaboração de futuras soluções (HARDENBERG, KORJONEN-KUUSIPURO \& PÁL, 2009, p. 17).

Por fim, é pertinente lembrarmos que fenômenos como desflorestamento e alterações climáticas sempre existiram, pois o planeta já passou por incontáveis transformações ao longo do tempo. Porém, o que está mudando é a intensidade e a amplitude dos fenômenos, sendo que alguns são ocasionados e/ou acelerados por ações antrópicas (BEVILACQUA, 1996, p. 161-196). A crítica da História Ambiental despertou a historiografia da convicção de que o tempo trabalha para nós. Estamos tomando consciência, por vezes de forma dolorosa, de que o futuro não está garantido por alguma teoria metafisica no progresso. O futuro está dramaticamente em nossas mãos e depende da nossa responsabilidade, sobretudo por meio de iniciativas sociais e ações governamentais que priorizem os interesses comuns e não apenas o ganho econômico para poucos.

\section{Referências}

ALFANI, Guido. Climate, Population and Famine in Northern Italy: general tendencies and malthusian crisis, ca. 1450 - 1800. Annales de Démographie Historique, Paris, vol. 2, n. 120, p. 23-53, 2010.

ALFANI, Guido; TULLIO, Matteo di; MOCARELLI, Luca. Storia economica e ambiente italiano (ca.1400 - 1850). Milano: Franco Angeli, 2012.

ARMIERO, Marco; BARCA, Stefania. La storia dell'ambiente: un'introduzione. Roma: Carocci, 2004.

BEVILACQUA, Piero. Demetra e Clio: uomini e ambiente nella storia. Roma: Donzelli Editora, 2001.

BEVILACQUA, Piero. Il secolo planetario: tempi e scansioni per una storia dell'ambiente. Parolechiave, Roma, n. 12, p. 161-196, 1996.

BEVILACQUA, Piero. Terre del grano, terre degli alberi: 1'ambiente nella storia del Mezzogiorno. Rionero di Volture: Calice, 1992. 
BEVILACQUA, Piero. Tra natura e storia: ambiente, economie, risorse in Italia. Roma: Donzelli, 1996.

BEVILACQUA, Piero; CORONA, Gabriella (orgs.). Ambiente e risorse nel Mezzogiorno contemporâneo. Corigliano Calabro: Meridiana Libri, 2000.

CARACCIOLO, Alberto. L'ambiente come storia: sondaggi e proposte di storiografia dell'ambiente. Bologna: Il Mulino, 1988.

CARACCIOLO, Alberto; BONACCHI, Gabriella M. (orgs.). Il declino degli elementi: ambiente naturale e rigenerazione delle risorse nell'Europa moderna. Bologna: Il Mulino, 1990.

CIPOLLA, Carlo Maria. Uomini, tecniche, economie. Milano: Feltrinelli, 1966.

FINZI, Roberto (org.). Le meteore e il frumento: clima, agricoltura, meteorologia a Bologna nel'700. Bologna: Il Mulino, 1986.

FONDAZIONE BASSO. L'ambiente nella storia d'Italia: immagini e documenti. Venezia: Marsilio, 1989.

GAMBI, Lucio. Una geografia per la storia. Torino: Einaudi, 1973.

HARDENBERG, Wilko Graf von; KORJONEN-KUUSIPURO, Kristiina; PÁL, Viktor. La storia ambientale nell'era dei problemi ecologici globali. Storia e Futuro, Bologna, n. 20, p. 01-22, 2009.

LUZZI, Saverio. Il virus del benessere: ambiente, salute, sviluppo nell'Italia republicana. Roma: Laterza, 2009.

MEADOWS, Donella. H.; MEADOWS, Dennis L.; RANDERS, Jørgen; BEHRENS III, William W. I limiti dello sviluppo: rapporto del System Dynamics Group Massachusetts Institute of Technology (MIT) per il progetto del Club di Roma sui dilemmi dell'umanità. Milano: Mondadori, 1972.

MEYER, Edgar H. I pionieri dell'ambiente: l'avventura del movimento ecologista italiano: cento anni di storia. Milano: Carabà, 1995.

MORENO, Diego. Dal documento al terreno: storia e archeologia dei sistemi agrosilvo-pastorali. Bologna: Il Mulino, 1990.

NEBBIA, Giorgio. La società dei rifiuti. Bari: Edipuglia, 1990.

NEBBIA, Giorgio. Per una definizione di storia dell'ambiente. Ecologia Politica CNS, n. 03, fasc. 27, anno 09, set./dic. 1999.

PAOLINI, Federico. Automobili e ambiente: verso una storia ambientale della mobilità? I Frutti di Demetra: bollettino di storia e ambiente, n. 21, p. 05-13, 2009. Disponível em: < 
http://www2.issm.cnr.it/demetrapdf/boll_21_2010/demetra_imp\%2021.pdf > . Acesso em: 27 maio 2017.

PAOLINI, Federico. Breve Storia dell'Ambiente nel Novecento. Roma: Carocci, 2009.

PAOLINI, Federico. La storia dell'ambiente in Italia: appunti sullo stato dell'arte.

Ricerche Storiche, n. 03, anno 41, p. 489-496, set./dic. 2011. Disponível em:

<http://www.polistampa.com/public/images/ricer116_3_16.pdf >. Acesso em: 27 maio 2017.

PAOLINI, Federico. Storia sociale dell'automobile in Italia. Roma: Carocci, 2007.

PAOLINI, Federico. Un paese a quattro ruote: automobili e società in Italia. Venezia: Marsilio, 2005.

PICCIONI, Luigi. Alla ricerca di una storia dell'ambientalismo italiano: il contributo di Giorgio Nebbia e Franco Pedrotti. Società e Storia, Prato, vol. 32, n. 124, p. 303-316, 2009.

PICCIONI, Luigi. Scritti di storia dell'ambiente e dell'ambientalismo (1970 - 2013). I quaderni di Altronovecento, n. 4. Fondazione Luigi Micheletti: Brescia, 2014.

PINTO, Giuliano; PONI, Carlo; TUCCI, Ugo (orgs.). L'Italia agricola dalle origini ad oggi, vol. II. Firenze: Accademia dei Georgofili; Polistampa, 2002.

PRATESI, Fulco. Storia della natura d'Italia. Roma: Editori Riuniti, 2001.

ROMANO, Ruggiero; VIVANTI, Corrado (orgs.). Storia d'Italia, vol. I: i caratteri originali. Torino: Einaudi, 1972.

SABA, Andrea Filippo; MEYER, Edgar H. Storia ambientale: una nuova frontiera storiografica. Milano: Teti Editore, 2001.

SCICHILONE, Laura. L'Europa e la sfida ecologica: storia della politica ambientale europea (1969-1998). Bologna: Il Mulino, 2008.

SERNERI, Simone Neri. Incorporare la natura: storie ambientali del Novecento. Roma: Carocci, 2005.

SERENI, Emilio. La storia del paesaggio agrario italiano. Bari: Laterza, 1961.

SERNERI, Simone Neri (org.). Storia del territorio e storia dell'ambiente: la Toscana contemporânea. Milano: Franco Angeli, 2002.

VARNI, Angelo. Storia dell'ambiente in Italia tra Ottocento e Novecento. Bologna: Il Molino, 1999.

WHITE JR., Lynn. Le radici storico-culturali della nostra crisi ecologica. Rivista Il Mulino, n. 22, p. 251-263, mar./apr. 1973. Este artigo é uma tradução do original publicado pelo autor na revista Science, em 10 de março de 1967. 